\title{
Updated guide to southern Africa's fern flora
}

BOOK TITLE:

Ferns of southern Africa: A comprehensive guide

\section{AUTHORS: \\ Neil Crouch \\ Ronell Klopper \\ John Burrows \\ Sandra Burrows}

ISBN:

9781770079106

\section{PUBLISHER:}

Struik Nature, Cape Town, R420

\section{PUBLISHED:}

2011

\section{REVIEW TITLE:}

Updated guide to southern Africa's fern flora

\section{REVIEWER:}

Brian W. van Wilgen

\section{AFFILIATION:}

CSIR Natural Resources and the Environment, Stellenbosch, South Africa

EMAIL:

bvwilgen@csir.co.za

\section{POSTAL ADDRESS:}

CSIR Natural Resources and the Environment, PO Box 320 , Stellenbosch 7599, South Africa

\section{HOW TO CITE:}

Van Wilgen BW. Updated guide to southern Africa's fern flora. S Afr J Sci. 2013;109(7/8), Art. \#a0024, 1 page. http://dx.doi. org/10.1590/sajs.2013/a0024
Southern Africa is home to a remarkable profusion of plants and animals, living in habitats that range from rainforests to deserts. The region's flora includes well over 20000 plant species; this wealth, combined with a long history of botanical exploration, has in turn spawned literally hundreds of botanical books. These books deal with different taxonomic groups of plants, plant forms such as trees, grasses or succulents, and regional floras and field guides. Ferns make up a small but important proportion of the region's flora, totalling over 300 species. It is not surprising, therefore, that there are already a number of books that have been dedicated to ferns. The first was T.R. Sim's The Ferns of South Africa, published in 1892. This was followed by, among others, E.A.C.L.E. Schelpe's A Revised Checklist of the Pteridophyta of Southern Africa in 1969, W.B.G. Jacobsen's The Ferns and Fern Allies of Southern Africa in 1983, and J.E. Burrows' Southern African Ferns and Fern Allies in 1990. Crouch et al.'s Ferns of Southern Africa is a completely revised and updated version of Burrows' 1990 publication.

Ferns are normally associated with forest environments, but they occur in a remarkably wide variety of habitats, including deserts, as this comprehensive treatment reveals. Each species is covered in a double-page spread, with a full plate of multiple photographs, including close-ups. There are tables that highlight differences between similar-looking species. Besides accurate descriptions of each species, there are several colour photographs, including photographs of typical habitat. Distribution maps, based on the author's extensive field work over several decades, are provided, and there are brief notes on what is known of the ecology of each species. This guide covers all 315 ferns known to occur in South Africa, Swaziland, Lesotho, Botswana and Namibia. This is fewer than the 343 species covered by Burrows' 1990 treatment of the subject, presumably because the earlier book included Zimbabwe and southern Mozambique, whereas this one does not. As is normal for any updated treatment of species, some ferns are described here for the first time - four new fern species discovered during the compilation of the book, and five more described for the first time.

The capacity to produce comprehensive treatments in a semi-popular format such as this book is found in a small number of scientists active in the field of taxonomy. Given that there are tens of thousands (maybe more) of species on earth that still await formal description, biologists today widely recognise both the importance of taxonomy as a science, and how poorly equipped we are to deal with it. To produce books such as this requires not only the existence of a sound set of descriptions produced by a small body of workers, but also a high level of enthusiasm and perseverance for locating specimens in the field. The authors have travelled extensively in the region, and have taken more than 30000 photographs. For most of the 20th century, books of this nature relied on talented botanical artists, and the quality of photographs was generally poor. The advances made in the field of digital photography have paved the way for producing the clear and varied images in this book. The authors state (somewhat modestly) that 'with the exception of Ophioglossum gracile and Christella altissima, we have seen all the ferns described in this book growing in the wild'. For $C$. altissima this is not surprising, as the species is thought to be extinct, while 0 . gracile is a somewhat rare, cryptic species from the fynbos that the authors clearly looked for (there are photographs of typical habitat) but were presumably unable to find. I can imagine their frustration. This book will certainly remain the standard reference book on local ferns for several decades. 